\title{
Bancos e crédito: a abordagem pós- keynesiana de preferência pela liquidez
}

Luiz Fernando de Paula ${ }^{1}$

Resumo: O artigo objetiva apresentar a teoria da preferência pela liquidez dos bancos desenvolvida por economistas pós-keynesianos. Para tanto, procura-se desenvolver as idéias originais de Keynes sobre o assunto, para em seguida incorporar as contribuições de outros autores pós-keynesianos. As implicações desta abordagem sobre as estratégias dos bancos e sobre o volume de crédito são também exploradas no texto.

Palavras-chave: bancos; preferência pela liquidez; crédito; teoria póskeyanesiana.

\section{Banking and credit: the post-Keynesian approach to liquidity preference}

\begin{abstract}
The essay presents the theory of banks liquidity preference as developed by post-Keynesian economists. It starts by using Keynes' ideas on the subject and adds the contribution of post-Keynesian economists. The essay closes with a discussion of the implications this approach will draw on banks strategies and on the volume of credit.
\end{abstract}

Key words: banks; liquidity preference; credit; post-Keynesian economics.

JEL: E41; E44

1 Professor da Faculdade de Ciências Econômicas da Universidade do Estado do Rio de Janeiro (FCE/UERJ) e pesquisador do CNPq. E-mail: luizfpaula@terra.com.br. Sítio: http:// paginas.terra.com.br/educacao/luizfpaula. 


\section{Introdução}

Na perspectiva de Keynes e na tradição pós-keynesiana, bancos são vistos como entidades que, mais do que meras intermediárias passivas de recursos, são capazes de criar crédito independentemente da existência de depósitos prévios, por meio da criação ativa de moeda bancária. O comportamento dos bancos - como uma firma que possui expectativas e motivações próprias - tem um papel essencial na determinação das condições de financiamento de uma economia capitalista, ao estabelecer o volume e as condições sob os quais o crédito é ofertado. Como qualquer firma capitalista, bancos têm como principal objetivo a obtenção de lucro na forma monetária. Para tanto, tomam suas decisões de portfólio orientadas pela expectativa de maiores lucros, levando em conta sua preferência pela liquidez e suas avaliações sobre a riqueza financeira, em condições de incerteza que caracterizam uma economia monetária da produção. Deste modo, os bancos enfrentam a escolha básica entre satisfazer os compromissos de empréstimos e preservar a flexibilidade para maximizar a liquidez de seu ativo em um ambiente adverso.

O presente artigo objetiva apresentar a teoria da preferência pela liquidez dos bancos desenvolvida por economistas pós-keynesianos a partir do trabalho original de Keynes. As implicações sobre as estratégias dos bancos e sobre o volume de crédito são também exploradas no paper. Para tanto, o artigo está dividido em três seções, além desta introdução. A seção 2 analisa a atividade bancária e a preferência pela liquidez dos bancos na visão original de Keynes. Na seqüência, a seção 3 aprofunda a abordagem da preferência pela liquidez dos bancos, incorporando contribuições de autores pós-keynesianos. A seção 4, por sua vez, faz algumas breves considerações sobre o comportamento dos bancos no Brasil no período pós-real. Por fim, há a conclusão do artigo.

\section{Atividade bancária e preferência pela liqüidez dos bancos em Keynes}

Keynes, em sua Teoria Geral, formulou sua teoria da preferência pela liquidez, ${ }^{2}$ em que a taxa de juros é "a recompensa por abrir-se mão da liquidez, uma medida do desejo daqueles que possuem moeda de abrir mão do seu controle sobre ela" (Keynes 1973:167), em um modelo em que havia somente duas classes de ativos: moeda e títulos. A moeda é

2 Para uma análise sobre a teoria da preferência pela liquidez de Keynes, ver, entre outros, Wells (1983). 
uma forma de riqueza e a taxa de juros o preço que guia a escolha entre forma líquida e ilíquida de riqueza. Nesse modelo, os juros pagos aos títulos são uma compensação pelo seu menor grau de liquidez quando comparado com a moeda, que possui o maior prêmio de liquidez entre os ativos. Em uma economia monetária, os agentes retêm moeda, seja porque têm planos de gastos para financiar (motivo transação), seja porque estão especulando sobre o comportamento futuro da taxa de juros (motivo especulação), ou ainda por precaução contra um futuro incerto, uma vez que a moeda é um ativo seguro com o qual se pode transportar a riqueza no tempo (motivo precaução). Assim, tanto a demanda precaucionária por moeda quanto a especulativa se definem por causa da incerteza quanto ao futuro.

No capítulo 17 da Teoria Geral, Keynes generalizou sua teoria da preferência pela liquidez para uma teoria de precificação de ativos, não mais presa em uma dicotomia entre ativos líquido e ilíquido, mas baseada no princípio geral de que os diferentes graus de liquidez devem ser compensados pelos retornos pecuniários que definem a taxa de retorno obtida pela posse dos diferentes ativos. ${ }^{3}$ Assim, cada classe de ativos existentes possui sua própria taxa de juros, definida em termos de preços correntes de mercado, em que:

$r_{A}=a+q-c+l$,

onde:

$q=$ rendimento do ativo (taxa de quase-renda a ser ganha pela posse ou uso do ativo);

$c$ = custo de carregamento incorrido na sua conservação;

$l=$ seu prêmio de liquidez;

$a=$ seu valor de mercado (taxa de apreciação).

Nesta abordagem, a preferência pela liquidez é refletida em termos do trade off entre retornos monetários $(a+q-c)$ e o prêmio pela liquidez da moeda $(l)$, causando assim substituições na estrutura de demanda por ativos, que se diferenciam de acordo com combinações de retornos monetários e prêmio de liquidez que eles oferecem, sendo a liquidez valorizada quando a incerteza aumenta.

Tal como no capítulo 17 da Teoria Geral, pode-se expressar a preferência pela liquidez de um banco numa cesta específica de ativos escolhidos por ele, de acordo com os diferentes graus de liquidez associados aos vários ativos ao alcance deles. ${ }^{4}$ Neste sentido, Keynes (1971, v.II:

3 Em equilíbrio, os retornos oferecidos por parte de cada classe de ativos - sua "taxa própria de juros" - teriam que ser iguais, o que implica que cada classe de ativos deve oferecer retornos em dinheiro proporcionais ao adicional de risco de iliquidez que cada classe oferece.

4 Para uma análise da abordagem da preferência pela liquidez dos bancos, ver Carvalho (1999). 
67), no Treatise on Money, já havia assinalado que o problema dos bancos no que se refere ao gerenciamento bancário no lado do ativo dizia respeito à composição de seu portfólio de aplicações:

O que bancos estão ordinariamente decidindo não é quanto eles emprestarão no agregado - isto é determinado por eles pelo estado de suas reservas - mas quais formas eles emprestarão - em que proporção eles dividirão seus recursos entre os diferentes tipos de investimentos que estão abertos para eles.

Assim, Keynes (1971, v.II, cap. 25) divide as aplicações, de forma ampla, em três categorias: (i) letras de câmbio e call loans (empréstimos de curtíssimo prazo no mercado monetário); (ii) investimentos (aplicações em títulos de terceiros, públicos ou privados); (iii) adiantamentos para clientes (empréstimos em geral). Quanto à rentabilidade dos ativos, os adiantamentos, via de regra, são mais lucrativos do que os investimentos, e estes, por sua vez, mais lucrativos do que os títulos e call loans, embora esta ordem não seja invariável. Quanto à liquidez, as letras de câmbio e os call loans são mais líquidos que os investimentos, ${ }^{5}$ pois são revendáveis no curto prazo sem perdas significativas, enquanto os investimentos são em geral mais líquidos que os adiantamentos. Estes últimos incluem vários tipos de empréstimos diretos e são, em geral, as aplicações mais lucrativas, mas, em contrapartida, mais arriscadas (quanto ao retorno do capital) e ilíquidas (por serem de mais longo termo e nãocomercializáveis). O Quadro 1 abaixo sintetiza o portfólio de aplicações dos bancos, segundo a rentabilidade e o grau de liquidez dos ativos.

Quadro 1 - Portfólio de aplicações, segundo Keynes (1971)

\begin{tabular}{ccc}
\hline ATIVO & RENTABILIDADE & GRAU DE LIQUIDEZ \\
\hline Letras de câmbio e call loans & pequena & alta \\
Investimentos & pequena & média \\
Adiantamentos & alta & pequena \\
\hline
\end{tabular}

Tal análise, quando compatibilizada com a teoria de decisões dos agentes sob condições de incerteza, aprofundada e desenvolvida por Keynes (1973, 1987) em trabalhos posteriores ao Treatise on Money, permite

5 A liquidez dos diversos ativos, segundo Davidson (1978), é determinada em função dos seguintes fatores: (i) tempo de conversibilidade, ou seja, o tempo gasto necessário para transformar o ativo em moeda; (ii) capacidade esperada de retenção do valor do ativo, relacionada à habilidade de um ativo transformar-se em moeda sem perda considerável de seu valor. Quanto menor o tempo gasto esperado de negociação e maior a capacidade esperada de reter valor de um ativo, mais elevada será a sua liquidez. O que determina a liquidez, em última instância, é a existência de mercados de revenda organizados, ou seja, mercados de "segunda mão." A moeda é, por definição, o ativo mais líquido da economia. 
enfocar as estratégias dos bancos (e tomada de decisões) com relação ao seu portfólio de aplicações considerando sua preferência pela liquidez. Bancos, como qualquer outro agente cuja atividade seja especulativa e demande algum grau de proteção e cuidado, têm preferência pela liquidez e conformam seu portfólio buscando conciliar lucratividade com sua escala de preferência pela liquidez, que expressa a precaução de uma firma cuja atividade tenha resultados incertos. ${ }^{6}$ É, portanto, da escolha de que ativos comprar e que obrigações emitir, orientada pela combinação entre liquidez e rentabilidade, que resulta a expansão ou contração da oferta de moeda, uma vez que a moeda é criada quando os bancos compram ativos financiados pela emissão de uma obrigação particular destas instituições - os depósitos à vista.

As expectativas dos bancos, sob condições de incerteza, têm um papel crucial na determinação da composição do portfólio de aplicações dos bancos, ou seja, seu ativo. Os bancos demandam aplicações mais líquidas, apesar de menos lucrativas, em função da incerteza sobre as condições que vigoram no futuro, o que pode levar a um aumento em sua preferência pela liquidez, ocasionando, conseqüentemente, um redirecionamento em sua estrutura de ativos. Moeda legal e ativos líquidos - cujo retorno vem na forma de um prêmio de liquidez mais do que uma compensação pecuniária - representam um instrumento de proteção à incerteza e de redução dos riscos intrínsecos à atividade bancária. A retenção de ativos líquidos permite aos bancos manter opções abertas, inclusive para especular no futuro.

Assim, as proporções em que as diferentes aplicações são divididas sofrem grandes flutuações, refletindo as expectativas dos bancos quanto à rentabilidade e liquidez de seus ativos, assim como ao estado geral de negócios na economia. Quando suas expectativas forem otimistas, os bancos privilegiarão rentabilidade à liquidez, procurando elevar prazos e submeter-se a maiores riscos com relação a seus ativos, diminuindo a margem de segurança (ativos líquidos/ativos ilíquidos) nas suas operações, o que resulta no crescimento da participação dos adiantamentos e de ativos de maior risco na composição de sua estrutura ativa, como os empréstimos de mais longo termo. ${ }^{7}$ Do contrário, se suas expectativas são pessimistas e a incerteza é alta, pois o grau de confiança nas suas expectativas quanto ao futuro diminui, eles expressam sua maior preferência pela liquidez dirigindo suas aplicações para ativos menos lucrativos porém mais líquidos, o que faz declinar a oferta de crédito aos seus clientes. Mais especificamente, procurarão reduzir o

6 Portanto, é a incerteza incontornável quanto ao futuro que justifica a preferência pela liquidez dos agentes, mantendo riqueza sob a forma de moeda.

7 Ao mesmo tempo, como será visto na seção 3 , os bancos podem se utilizar de métodos de administração de passivos para alavancar suas operações ativas. 
prazo médio de seus ativos e adotar uma posição mais líquida, por meio da manutenção de reservas excedentes ou compra de ativos de grande liquidez, como os papéis do governo, diminuindo em contrapartida a participação de adiantamentos no total do ativo e privilegiando as aplicações em ativos mais líquidos e de menor risco.

Deste modo, as estratégias bancárias procuram explorar o trade off rentabilidade e liquidez: em geral, um banco, ao privilegiar liquidez em detrimento de maior rentabilidade, deverá caminhar na direção de ativos mais líquidos; alternativamente, ao buscar maior rentabilidade, deverá procurar ativos de mais longo termo ou de mais alto risco. ${ }^{8}$ Assim, bancos com preferência pela liquidez poderão não acomodar passivamente a demanda por crédito, pois buscarão comparar os retornos esperados com os prêmios de liquidez de todas os ativos que podem ser comprados. A sensibilidade dos bancos em relação às demandas de crédito por parte do público depende, em grande medida, das preferências que orientam as suas decisões de portfólio. Como mostra Keynes (1971, v.II:67), tal sensibilidade pode ser suficientemente elástica por parte dos bancos:

Quando (...) as demandas por adiantamentos aumentam por parte de seus clientes de negócios de uma forma que os bancos julguem legítima ou desejável, eles fazem o máximo para satisfazer estas demandas reduzindo seus investimentos e, talvez, suas letras de câmbio; enquanto, se a demanda por adiantamentos está caindo, eles empregam os recursos mais livremente, aumentando de novo seus investimentos.

\section{Comportamento dos bancos e oferta de crédito: a abordagem da preferência pela liquidez}

Na abordagem pós-keynesiana, tomando como base a abordagem pioneira de Keynes, os bancos - como qualquer outra firma capitalista tomam suas decisões de portfólio orientados pela perspectiva por maiores lucros, levando em conta sua preferência pela liquidez e suas avaliações sobre a riqueza financeira em condições de incerteza que caracterizam uma economia monetária da produção. ${ }^{9}$ De tal escolha depende,

8 A taxa de risco $(r)$ associada à posse de um ativo está relacionada negativamente ao seu prêmio de liquidez $(l)$, que mede a dificuldade de disposição do ativo no caso de mudança do portfólio.

9 Uma economia monetária da produção tem como característica central o destaque dado ao processo de tomada de decisões em um ambiente de incerteza não-probabilística, à concepção de nãoneutralidade da moeda - segundo a qual a moeda não é uma simples conveniência, pois, sendo um ativo, afeta motivos e decisões dos agentes - e, ainda, ao sistema de contratos a prazo, por meio de resgates de pagamentos no futuro, como instrumento básico pelo qual os agentes alcançam algum tipo de coordenação perante o futuro incerto (cf. Carvalho 1992). 
em boa medida, a criação de crédito e depósitos bancários, e, por conseguinte, a oferta de moeda na economia.

Bancos são agentes econômicos cuja preferência pela liquidez é fortemente determinada por suas expectativas sob incerteza nãoprobabilística, ${ }^{10}$ conformando seu portfólio de acordo com o trade-off entre liquidez e rentabilidade, como visto na seção anterior. Sua posição na escala de preferência pela liquidez reflete sua precaução inerente aos resultados incertos da atividade bancária vis-à-vis os retornos da aplicação do seu portfólio. Assim, de acordo com a abordagem da preferência pela liquidez, a estratégia do banco é definida de acordo com a sua percepção de risco e oportunidades de lucro: "Para um dado estado de expectativas, a preferência pela liquidez dos bancos determinará o lucro desejado dos ativos que eles compram e seus preços; isto é, a taxa de retorno de cada tipo de ativo deve compensar seu desejo por iliquidez" (Carvalho 1999:132).

Bancos com preferência pela liquidez podem não acomodar a demanda por crédito passivamente, pois buscarão comparar os retornos esperados e os prêmios de liquidez de todos os ativos compráveis. Isto significa que a oferta de crédito pode ser restringida por causa de uma maior preferência pela liquidez dos bancos, independentemente do verdadeiro risco relacionado ao empréstimo bancário. O racionamento do crédito pode acontecer, assim, de forma independente dos retornos esperados sobre projetos de investimento (Dow 1996:503-4).

De acordo com a abordagem pós-keynesiana, bancos são vistos como agentes ativos que administram dinamicamente os dois lados de seus balanços. Isto significa que eles não tomam o seu passivo como dado, na medida em que procuram influenciar as preferências dos depositantes por meio do gerenciamento das obrigações e da introdução de inovações financeiras. ${ }^{11} \mathrm{O}$ banco moderno atua dinamicamente sobre o lado do passivo do balanço bancário, fazendo esforços na busca de novos depósitos e/ou gerenciando suas reservas, o que resulta em que os fundos que financiam seus ativos são parcialmente condicionados pelo próprio comportamento do banco. Assim, ao invés de receber passivamente depósitos de acordo com as preferências individuais dos clientes, os bancos procuram intervir nessas escolhas de várias maneiras, promovendo mudanças na estrutura do passivo de modo a obter vantagens das oportunidades lucrativas em seus negócios.

10 Incerteza não-probabilística no sentido Knight-Keynes se refere a fenômenos econômicos para os quais "não existe qualquer base científica para formar cálculos probabilísticos" (Keynes 1973: 114).

11 Ver, a respeito, Minsky (1986: cap. 10), Wray (1990) e Paula (1999). 
Os bancos desempenham um papel importante e contraditório no ciclo econômico, uma vez que seu comportamento é capaz de amplificar o crescimento econômico durante a fase expansionista do ciclo, enquanto que ele pode acentuar a desaceleração cíclica em tempos de crise. $\mathrm{Na}$ fase expansionista do ciclo, os bancos têm um papel central em sancionar as demandas por crédito das firmas, fundamental para que uma economia monetária possa crescer. Os banqueiros respondem as visões otimistas sobre a viabilidade de estruturas de dívidas das firmas - típicas de um contexto de crescimento - financiando as posições com um aumento em sua carteira de crédito. Seu comportamento - como uma firma que possui expectativas e motivações próprias - é essencial na determinação das condições de financiamento em uma economia capitalista.

Do ponto de vista do portfólio de aplicações dos bancos (ativo), como suas expectativas tornam-se mais otimistas na fase ascendente do ciclo, eles passam a privilegiar rentabilidade à liquidez, procurando elevar os prazos e adquirir ativos que embutem maiores riscos, diminuindo a relação entre ativos líquidos/ativos ilíquidos nas suas operações, o que resulta, por exemplo, no crescimento da participação dos adiantamentos e dos empréstimos de mais longo termo em seus portfólios. A busca por maiores lucros em uma conjuntura expansionista induz os bancos a adotar uma postura mais especulativa: o banqueiro procurará obter maior rendimento aceitando ativos de mais longo termo e/ou de mais alto risco e, ao mesmo tempo, diminuindo a taxa paga nas suas obrigações, oferecendo maiores promessas de segurança e garantias especiais aos depositantes e encurtando o termo das obrigações. Como resultado destas estratégias bancárias, a disponibilidade de recursos para o financiamento de gastos dos agentes aumenta, promovendo uma condição necessária para a expansão do nível de produto na economia.

Ao mesmo tempo, com vistas a alavancar suas operações ativas - em particular a concessão de empréstimos - os bancos passam a se utilizar ativamente de técnicas de administração do passivo, de modo a não só alterar a composição de seu passivo em uma direção que lhes seja mais conveniente, como também a aumentar o volume de recursos captados junto ao público. Isto é feito de duas formas: gerenciamento de reservas e introdução de inovações financeiras.

No primeiro caso, os bancos procuram induzir seus clientes a aplicar seus recursos em obrigações que economizem reservas - por exemplo, por meio do manejo das taxas de juros dos depósitos a prazo e, ainda, de outras formas indiretas de estímulo a um redirecionamento no comportamento do público, por intermédio de publicidade, oferecimento de prêmios aos clientes etc. - de modo a ter mais recursos disponíveis 
"livres" para emprestar. ${ }^{12}$ No segundo caso, os bancos procuram, por meio do lançamento de novos produtos e serviços, ou uma nova forma de oferecer um produto já existente - as chamadas inovações financeiras - adotar uma política mais agressiva de captação de fundos, buscando atrair novos recursos de modo a alavancar sua capacidade de atender uma expansão na demanda por crédito. As inovações financeiras, em um período de boas perspectivas de negócios para os bancos, resultam não apenas das instituições procurando contornar as regulamentações e restrições das autoridades monetárias, mas também da busca de recursos de terceiros para o financiamento de suas operações ativas.

O aumento no grau de alavancagem do banco, portanto, faz com que se busque novas formas de tomar fundos emprestados, de modo a permitir que as instituições bancárias cresçam mais rapidamente e aproveitem as oportunidades de lucros, sobretudo em períodos de maior otimismo nos negócios. Assim, como resultado de uma estratégia de expansão de suas operações ativas, os bancos elevam o grau de alavancagem de seu patrimônio, aumentando o uso de recursos de terceiros para adquirir ativos.

De fato, a maior alavancagem e o maior hiato temporal entre ativo/ passivo constituem uma posição mais arriscada e passam agora a integrar a estratégia do banco. Mesmo os bancos mais conversadores, estimulados pela competição e pelo menor risco percebido, precisam expandir seus empréstimos se eles não quiserem perder sua fatia no mercado. ${ }^{13} \mathrm{O}$ fator alavancagem afeta diretamente o volume de financiamento disponível, mas ao mesmo tempo aumenta a fragilidade do balanço do banco. Portanto, as técnicas de administração de passivo e o lançamento de inovações financeiras assumem um papel crucial na estratégia bancária na fase ascendente do ciclo econômico, procurando reduzir a necessidade de reservas e aumentar o volume de recursos de terceiros captados, de maneira compatível com a alavancagem dos empréstimos.

Enquanto na fase expansionista os bancos têm um papel central em sancionar as demandas por crédito das firmas, na fase descendente do ciclo eles cumprem um papel de amplificar o quadro de crise que se instala, uma vez que as estratégias defensivas adotadas resultam num racionamento de crédito que pode inviabilizar a rolagem da dívida por parte

12 Segundo Minsky (1986:243), "a habilidade de criar substitutos para reservas e para minimizar a absorção de reservas é uma propriedade essencial para um sistema bancário maximizador de lucros”.

13 De acordo com Kregel (1997:545), “a decisão de emprestar neste caso está baseada fundamentalmente na convenção ou opinião média (...), que significa estar referenciada aos tipos de projetos que os outros bancos estão financiando (...). Portanto, ao longo do tempo, os banqueiros estarão emprestando aos tomadores que eles previamente haviam recusado (ou teriam emprestado somente as mais elevadas margens de segurança), e eles estarão se concentrando em emprestar para projetos em áreas particulares simplesmente porque todos os demais bancos estão fazendo assim." 
das empresas não-financeiras. Quando a crise se inicia, a incerteza é alta (o estado de expectativas dos agentes se deteriora) e as expectativas dos bancos quanto ao futuro diminuem.

Os fluxos de rendimento esperados são reduzidos, uma vez que as instituições financeiras esperam uma diminuição nos retornos de seus empréstimos devido ao declínio nos lucros das firmas. Neste contexto, altera-se a avaliação de risco dos tomadores de crédito por parte dos bancos. Como o crescente risco percebido é incorporado ao prêmio de risco, os tomadores podem ser racionados via taxas de juros cobradas pelos (novos) empréstimos. O comportamento do sistema bancário pode agravar um eventual quadro de crise econômica, pois, ao procurar recuperar o mais rapidamente possível o crédito estendido às empresas, ele pode se recusar a rolar integralmente (ou parcialmente) os passivos das firmas, assim como o serviço da dívida. Isto pode resultar tanto em uma elevação na taxa de juros cobrada quanto em uma maior seletividade na concessão do crédito. Conseqüentemente, os empréstimos em atraso como um todo tendem a aumentar na economia.

As instituições bancárias passam a expressar sua maior preferência pela liquidez dirigindo suas aplicações para ativos menos lucrativos, porém mais líquidos, o que faz declinar a oferta de crédito aos seus clientes. Deste modo, os bancos procurarão reduzir o prazo médio de seus ativos e a adotar uma posição mais líquida, por meio da manutenção de reservas excedentes e/ou da compra de ativos de alta liquidez, como os papéis do governo, diminuindo em contrapartida a participação de adiantamentos no total do ativo, sobretudo os empréstimos de mais longo prazo. Do outro lado, a administração de passivo perde importância, ao mesmo tempo em que diminui o grau de alavancagem do banco, por intermédio de um aumento da participação relativa do patrimônio líquido no total do passivo, expressando a maior cautela do banco sob condições econômicas adversas.

Em particular, os bancos expressarão suas posturas mais conservadoras, procurando diminuir sua exposição aos riscos inerentes à atividade bancária, uma vez que seu estado de expectativas com relação às perspectivas da economia e dos negócios se deteriora. Por isso, procuram evitar ao máximo o descasamento de taxas e maturidades entre suas operações ativas e passivas, ao mesmo tempo em que se tornam mais cautelosos na concessão de crédito, inclusive solicitando maiores cauções (colaterais) neste tipo de operação.

Em outras palavras, como as expectativas quanto ao futuro se deterioram, os bancos tenderão a adotar posturas financeiras mais conservadoras frente ao maior risco percebido, o que se expressa no crescimento de sua preferência pela liquidez na composição de seu portfólio de aplicações. Ou seja, um banco, ao privilegiar liquidez em detrimento de 
maior rentabilidade, deverá caminhar na direção de ativos mais líquidos e de menor risco. Em suma, tendo em vista a sua preferência pela liquidez, os bancos poderão não acomodar passivamente a demanda por crédito, ${ }^{14}$ caso a comparação dos retornos esperados com os prêmios de liquidez de todas os ativos que podem ser comprados assim indicar. Nessas circunstâncias, as possibilidades de expansão da economia se tornam limitadas pela restrição de financiamento, enquanto perdurar um quadro de expectativas pessimistas.

\section{Algumas breves considerações sobre o comportamento dos bancos no Brasil}

No caso do comportamento dos bancos no período recente no Brasil, Paula et al. (2001) e Paula e Alves Jr. (2003) mostram que a abordagem da preferência pela liquidez é apropriada para analisar o processo de ajustamento dos bancos no período pós-Real. Dada a importância relativa dos títulos públicos indexados à taxa Selic e à taxa de câmbio no portfólio dos bancos, estes puderam, ao longo dos choques externos de 1997 a 2002, enfrentar esse contexto mantendo uma situação de equilíbrio financeiro saudável e sendo ao mesmo tempo lucrativos. O contexto macroinstitucional tem tido uma influência decisiva sobre tal comportamento no passado recente, com os bancos extraindo vantagens das altas taxas de juros e da forma pela qual o governo tem administrado a dívida pública interna.

De fato, a especificidade institucional da relação entre o Banco Central e o setor bancário no Brasil, no contexto do gerenciamento da dívida pública, permitiu que os bancos pudessem compor seu portfólio de tal forma que combinassem liquidez $e$ rentabilidade, mesmo em circunstâncias em que o volume de crédito dos bancos esteve relativamente baixo (ver Tabela 1). Os bancos puderam obter alta rentabilidade por meio das operações de crédito de maturidade curta (e freqüentemente amparadas em algum colateral), face aos elevados spreads obtidos, e nas aplicações em títulos públicos, que proporcionaram a eles um hedge contra o risco de taxa de juros e o risco cambial. Em outras palavras, a alocação de portfólio dos bancos tem estado dominada pelo

\footnotetext{
14 A própria natureza da demanda de crédito se altera durante o ciclo. Na fase expansionista, o crédito é demandado primordialmente para financiar compras e expansão da capacidade produtiva. Quando a economia entra numa fase de descenso, uma parte maior da demanda de crédito se origina na necessidade de renegociação de débitos atrasados, uma situação claramente mais arriscada.
} 
curtoprazismo e alta preferência pela liquidez, que tem resultado em baixa oferta de crédito e elevado spread. ${ }^{15}$

TABELA 1 - PORTFÓLIO DOS BANCOS (\% RELATIVA AO TOTAL DO ATIVO)

\begin{tabular}{ccccccccc}
\hline \multicolumn{1}{c}{ Total empréstimos/total de ativos } & \multicolumn{3}{c}{ Total títulos e valores mobil./total ativos } \\
\hline & Total & BPF & BPN & BPE & Total & BPF & BPN & BPE \\
\hline jun/98 & $41,8 \%$ & $55,1 \%$ & $39,9 \%$ & $39,5 \%$ & $36,5 \%$ & $24,3 \%$ & $34,6 \%$ & $37,3 \%$ \\
dez/98* & $43,6 \%$ & $55,2 \%$ & $41,2 \%$ & $44,0 \%$ & $31,0 \%$ & $35,9 \%$ & $38,9 \%$ & $36,7 \%$ \\
jun/99 & $43,0 \%$ & $54,0 \%$ & $39,4 \%$ & $42,2 \%$ & $38,2 \%$ & $31,9 \%$ & $35,8 \%$ & $35,1 \%$ \\
dez/99 & $44,0 \%$ & $53,5 \%$ & $41,8 \%$ & $42,2 \%$ & $37,9 \%$ & $29,7 \%$ & $36,4 \%$ & $36,6 \%$ \\
jun/oo & $47,1 \%$ & $55,1 \%$ & $45,0 \%$ & $46,7 \%$ & $37,8 \%$ & $30,8 \%$ & $35,1 \%$ & $36,0 \%$ \\
dez/oo & $47,8 \%$ & $56,5 \%$ & $47,2 \%$ & $38,4 \%$ & $37,5 \%$ & $26,0 \%$ & $36,0 \%$ & $48,1 \%$ \\
jun/o1** & $46,9 \%$ & $46,9 \%$ & $49,7 \%$ & $46,4 \%$ & $37,2 \%$ & $32,7 \%$ & $31,5 \%$ & $39,4 \%$ \\
dez/o1 & $44,2 \%$ & $37,3 \%$ & $49,9 \%$ & $46,4 \%$ & $43,1 \%$ & $46,0 \%$ & $33,3 \%$ & $43,3 \%$ \\
jun/o2 & $43,9 \%$ & $42,5 \%$ & $43,1 \%$ & $46,6 \%$ & $42,1 \%$ & $39,8 \%$ & $35,7 \%$ & $41,0 \%$ \\
dez/02 & $41,7 \%$ & $33,7 \%$ & $47,4 \%$ & $48,7 \%$ & $43,2 \%$ & $45,8 \%$ & $35,4 \%$ & $38,4 \%$ \\
jun/o3 & $42,6 \%$ & $35,5 \%$ & $49,2 \%$ & $49,7 \%$ & $41,8 \%$ & $45,0 \%$ & $32,7 \%$ & $35,9 \%$ \\
dez/o3 & $40,6 \%$ & $33,6 \%$ & $47,5 \%$ & $50,7 \%$ & $45,4 \%$ & $48,7 \%$ & $36,4 \%$ & $36,6 \%$ \\
jun/o4 & $42,6 \%$ & $35,4 \%$ & $51,1 \%$ & $49,9 \%$ & $42,4 \%$ & $44,7 \%$ & $31,2 \%$ & $37,5 \%$ \\
dez/04 & $43,5 \%$ & $38,0 \%$ & $50,1 \%$ & $50,1 \%$ & $41,5 \%$ & $43,2 \%$ & $31,4 \%$ & $36,8 \%$ \\
\hline
\end{tabular}

Fonte: Elaboração própria com base em dados do Banco Central do Brasil.

Obs.: BPN: 4 maiores bancos privados nacionais - Bradesco, Itaú, Unibanco e Safra; BPE: 6 maiores bancos estrangeiros - Santander, ABN-Amro, Bankboston, HSBC, Citibank, Sudameris (até dez/2003); BPF: 2 maiores bancos públicos federais (Banco do Brasil e CEF).

TOTAL: inclui todos os conglomerados financeiros públicos e privados.

(*) Exclui o ABN-Amro, cujos dados foram comprometidos por conta da absorção do Real.

$\left({ }^{* *}\right)$ Exclui o Santander, cujos dados foram comprometidos por conta da absorção do Banespa.

\section{Conclusão}

Este artigo objetivou apresentar a abordagem da preferência pela liquidez dos bancos, de acordo com teoria pós-keynesiana. Nesta perspectiva, os bancos, como uma firma capitalista cujo objetivo principal é obter lucro na forma monetária e que possui preferência pela liquidez, é uma instituição cujo comportamento influencia diretamente as condições de liquidez e de financiamento da economia, e, por conseguinte, a concretização das decisões de gastos dos agentes. A volatilidade de suas avaliações sobre a riqueza financeira e suas expectativas quanto ao retorno dos empréstimos ocasionam flutuações na oferta de crédito e, conseqüentemente, nos níveis de investimento, produto e emprego na economia.

15 O próprio spread bancário é influenciado pelas decisões de portfólio, neste contexto macroinstitucional, considerando que os bancos passam a embutir um elevado prêmio de risco em seus empréstimos em função do alto custo de oportunidade de emprestar, face a existência de uma opção da aplicação que garante um patamar mínimo de remuneração com elevada liquidez, representado pelos títulos públicos indexados. 


\section{Referências}

CARVALHO, F. C. (1992). Mr. Keynes and the post Keynesians. Cheltenham: Edward Elgar.

CARVALHO, F. C. (1999). “On bank's liquidity preference”. In DAVIDSON, P. \& KREGEL, J. (eds). Full employment and price stability in a global economy. Cheltenham: Edward Elgar.

DAVIDSON, P. (1978). Money and the real world. London: Macmillan, $2^{\text {nd }}$ edition.

DOW, S. (1996). "Horizontalism: a critique”. Cambridge Journal of Economics 20: 497-508.

KEYNES, J.M. (1971). A treatise on money, vol. I e II. Londres: Macmillan.

(1973). The general theory of employment, interest and money. Londres: Macmillan.

(1987). "The general theory of employment". In The general theory and after: defence and development. Londres: Macmillan.

KREGEL, J. (1997). "Margins of safety and weight of the argument in generating financial instability". Journal of Economic Issues 31(2): 543-48.

MINSKY, H. (1986). Stabilizing an unstable economy. New Haven: Yale University Press.

PAULA, L.F. (1999). "Dinâmica da firma bancária: uma abordagem nãoconvencional." Revista Brasileira de Economia 53(3): 323-56.

PAULA, L. F. \& ALVES Jr., A. J. \& MARQUES, M. B. (2001). “Ajuste patrimonial e padrão de rentabilidade dos bancos privados no Brasil durante o Plano Real (1994-1998)”. Estudos Econômicos 31(2): 285-319.

PAULA, L. F \& ALVES Jr., A. (2003). "Banking behaviour and the Brazilian economy after the Real Plan: a Post-Keynesian approach”. Banco Nazionale del Lavoro Quarterly Review 227: 337-65.

WELLS, P. (1983). "A post Keynesian view of liquidity preference and the demand of money". Journal of Post Keynesian Economics 5(4): 523-37.

WRAY, L. (1990). Money and credit in capitalist economies: the endogenous money approach. Aldershot: Edward Elgar.

Artigo recebido em 01/08/2006. Aceite em 29/08/2006. 